\title{
CARACTERIZAÇÃO DE POÇAS DE MARÉ E LEVANTAMENTO TAXONÔMICO DE MACROBENTÔNICOS NA PRAIA COSTA AZUL, EM IRIRI-ES
}

\author{
Annie da Silva Cassamali ${ }^{1}$ \\ Luan de Oliveira Cerqueira ${ }^{2}$ \\ Adriane Araújo Braga ${ }^{3}$ \\ Erika Takagi Nunes ${ }^{4}$
}

Resumo: Estudos envolvendo poças de maré são bem escassos, e em sua maioria são relacionados à ictiofauna destes lugares. Nesse sentido, o presente trabalho visou caracterizar os diferentes tipos de poças de maré quanto aos fatores abióticos, bem como, verificar os organismos macrobentônicos presentes em duas poças (PA, PB) do costão rochoso, localizado na Praia Costa Azul, em Iriri - ES. Para coleta foi utilizado um quadrante de $15 \times 15 \mathrm{~cm}$, o qual foi lançado no começo, meio e fim de cada poça. Foram realizadas três coletas (abril, junho e agosto/2016). A partir dos dados gerados pelo Programa Past, foi possível observar que a poça de maré $A$ possui maior diversidade e equidade, enquanto que a poça $B$ possui maior abundância e riqueza de indivíduos da fauna macrobentônica.

Palavras-chave: Fauna; Macroalgas; Costão rochoso; Diversidade.

\footnotetext{
${ }^{1}$ Ciências Biológicas/Universidade Federal do Espírito Santo, Brasil. E-mail: anniecassamali@hotmail.com. ${ }^{2}$ Ciências Biológicas/Universidade Federal do Espírito Santo, Brasil. E-mail: luaano@hotmail.com.

${ }^{3}$ Departamento de Biologia/ Universidade Federal do Espírito Santo, Brasil. E-mail: dricrab@yahoo.com.br.

${ }^{4}$ Departamento de Biologia/ Universidade Federal do Espírito Santo, Brasil. E-mail: erikatnunes@gmail.com.
} 